\title{
Caregiver Perspectives on Communication During Hospitalization at an Academic Pediatric Institution: A Qualitative Study
}

\author{
Lauren G. Solan, MD, MEd, Andrew F. Beck, MD, MPH'1,2, Stephanie A. Shardo, BS1, Hadley S. Sauers-Ford, MPH'1, \\ Jeffrey M. Simmons, MD, MSc ${ }^{1}$, Samir S. Shah, MD, MSCE ${ }^{1,3}$, Susan N. Sherman, DPA ${ }^{4}$, on behalf of the H2O Study Group
}

\begin{abstract}
${ }^{1}$ Cincinnati Children's Hospital Medical Center, Division of Hospital Medicine, Cincinnati, Ohio. Lauren G. Solan is now with the University of Rochester Medical Center, Division of Pediatric Hospital Medicine, Rochester, New York. Hadley S. Sauers-Ford is now with UC Davis Health System, Pediatric Telemedicine, Sacramento, California. Stephanie A. Shardo is now with Summa Akron City Hospital, Cooper Cancer Center, Akron, Ohio; ${ }^{2}$ Cincinnati Children's Hospital Medical Center, Division of General and Community Pediatrics, Cincinnati, Ohio; ${ }^{3}$ Cincinnati Children's Hospital Medical Center, Division of Infectious Diseases, Cincinnati, Ohio; ${ }^{4}$ SNS Research, Cincinnati, Ohio.
\end{abstract}

OBJECTIVE: Communication among those involved in a child's care during hospitalization can mitigate or exacerbate family stress and confusion. As part of a broader qualitative study, we present an in-depth understanding of communication issues experienced by families during their child's hospitalization and during the transition to home.

METHODS: Focus groups and individual interviews stratified by socioeconomic status included caregivers of children recently discharged from a children's hospital after acute illnesses. An open-ended, semistructured question guide designed by investigators included communication-related questions addressing information shared with families from the medical team about discharge, diagnoses, instructions, and care plans. By using an inductive thematic analysis, 4 investigators coded transcripts and resolved differences through consensus.

RESULTS: A total of 61 caregivers across 11 focus groups and 4 individual interviews participated. Participants were $87 \%$ female and $46 \%$ non-white. Analyses resulted in 3 communication-related themes. The first theme detailed experiences affecting caregiver perceptions of communication between the inpatient medical team and families. The second revealed communication challenges related to the teaching hospital environment, including confusing messages associated with large multidisciplinary teams, aspects of family-centered rounds, and confusion about medical team member roles. The third reflected caregivers' perceptions of communication between providers in and out of the hospital, including types of communication caregivers observed or believed occurred between medical providers.

CONCLUSIONS: Participating caregivers identified various communication concerns and challenges during their child's hospitalization and transition home. Caregiver perspectives can inform strategies to improve experiences, ease challenges inherent to a teaching hospital, and determine which types of communication are most effective. Journal of Hospital Medicine 2018;13:304310. Published online first January 18, 2018. (c) 2018 Society of Hospital Medicine rovision of high-quality, high-value medical care hinges upon effective communication. During a hospitalization, critical information is communicated between patients, caregivers, and providers multiple times each day. This can cause inconsistent and misinterpreted messages, leaving ample room for error. ${ }^{1}$ The Joint Commission notes that communication failures occurring between medical providers account for $\sim 60 \%$ of all sentinel or serious adverse events that result in death or harm to a patient. ${ }^{2}$ Communication that occurs between patients and/or their caregivers and medical providers is also critically important. The content and consistency of this communication is highly valued by patients

\footnotetext{
*Address for correspondence: Lauren G. Solan, MD, MEd, Division of Pediatric Hospital Medicine, University of Rochester Medical Center, 601 Elmwood Avenue, Box 667, Rochester, NY 14642; Telephone: 585-275-6819; Fax: 585-2761128; E-mail: lauren_solan@urmc.rochester.edu
}

Received: May 15, 2017; Revised: August 11, 2017; Accepted: August 18, 2017 2018 Society of Hospital Medicine DOI 10.12788/jhm.2919 and providers and can affect patient outcomes during hospitalizations and during transitions to home.,4, Still, the multifactorial, complex nature of communication in the pediatric inpatient setting is not well understood. ${ }^{5,6}$

During hospitalization, communication happens continuously during both daytime and nighttime hours. It also precedes the particularly fragile period of transition from hospital to home. Studies have shown that nighttime communication between caregivers and medical providers (ie, nurses and physicians), as well as caregivers' perceptions of interactions that occur between nurses and physicians, may be closely linked to that caregiver's satisfaction and perceived quality of care. ${ }^{6,7}$ Communication that occurs between inpatient and outpatient providers is also subject to barriers (eg, limited availability for direct communication) ${ }^{8-12}$; studies have shown that patient and/or caregiver satisfaction has also been tied to perceptions of this communication. ${ }^{13,14}$ Moreover, a caregiver's ability to understand diagnoses and adhere to postdischarge care plans is intimately tied to communication during the hospitalization and at discharge. Although many improvement efforts have 
aimed to enhance communication during these vulnerable time periods, ${ }^{3,15,16}$ there remains much work to be done. ${ }^{1,10,12}$

The many facets and routes of communication, and the multiple stakeholders involved, make improvement efforts challenging. We believe that more effective communication strategies could result from a deeper understanding of how caregivers view communication successes and challenges during a hospitalization. We see this as key to developing meaningful interventions that are directed towards improving communication and, by extension, patient satisfaction and safety. Here, we sought to extend findings from a broader qualitative study ${ }^{17}$ by developing an in-depth understanding of communication issues experienced by families during their child's hospitalization and during the transition to home.

\section{METHODS}

\section{Setting}

The analyses presented here emerged from the Hospital to Home Outcomes Study ( $\mathrm{H} 2 \mathrm{O}$ ). The first objective of $\mathrm{H} 2 \mathrm{O}$ was to explore the caregiver perspective on hospital-to-home transitions. Here, we present the results related to caregiver perspectives of communication, while broader results of our qualitative investigation have been published elsewhere. ${ }^{17}$ This objective informed the latter 2 aims of the $\mathrm{H} 2 \mathrm{O}$ study, which were to modify an existing nurse-led transitional home visit (THV) program and to study the effectiveness of the modified THV on reutilization and patient-specific outcomes via a randomized control trial. The specifics of the $\mathrm{H} 2 \mathrm{O}$ protocol and design have been presented elsewhere. ${ }^{18}$

$\mathrm{H} 2 \mathrm{O}$ was approved by the Institutional Review Board at Cincinnati Children's Hospital Medical Center (CCHMC), a free-standing, academic children's hospital with $\sim 600$ inpatient beds. This teaching hospital has $>800$ total medical students, residents, and fellows. Approximately 8000 children are hospitalized annually at CCHMC for general pediatric conditions, with $\sim 85 \%$ of such admissions staffed by hospitalists from the Division of Hospital Medicine. The division is composed of $>40$ providers who devote the majority of their clinical time to the hospital medicine service; 15 additional providers work on the hospital medicine service but have primary clinical responsibilities in another division.

Family-centered rounds (FCR) are the standard of care at CCHMC, involving family members at the bedside to discuss patient care plans and diagnoses with the medical team. ${ }^{19} \mathrm{On}$ a typical day, a team conducting FCR is composed of 1 attending, 1 fellow, 2 to 3 pediatric residents, 2 to 3 medical students, a charge nurse or bedside nurse, and a pharmacist. Other ancillary staff, such as social workers, care coordinators, nurse practitioners, or dieticians, may also participate on rounds, particularly for children with greater medical complexity.

\section{Population}

Caregivers of children discharged with acute medical conditions were eligible for recruitment if they were English-speaking (we did not have access to interpreter services during focus groups/interviews), had a child admitted to 1 of 3 services (hos-
TABLE 1. Participant Demographics

\begin{tabular}{|c|c|}
\hline \multicolumn{2}{|c|}{ Focus Group and Interview Participants Demographics $(N=61)$} \\
\hline Gender & $\mathrm{N}(\%)$ \\
\hline Male & $8(13)$ \\
\hline Female & $53(87)$ \\
\hline \multicolumn{2}{|l|}{ Age range (years) } \\
\hline $18-24$ & $5(8)$ \\
\hline $25-34$ & $28(46)$ \\
\hline $35-44$ & $22(36)$ \\
\hline $45-54$ & $6(10)$ \\
\hline \multicolumn{2}{|l|}{ Marital status } \\
\hline Single & $22(36)$ \\
\hline Single, living with partner & $8(13)$ \\
\hline Married & $24(39)$ \\
\hline Separated, divorced, widowed & $7(11)$ \\
\hline \multicolumn{2}{|l|}{ Race } \\
\hline Black or African American & $25(41)$ \\
\hline White & $33(54)$ \\
\hline Other & $3(5)$ \\
\hline \multicolumn{2}{|l|}{ Ethnicity } \\
\hline Non-Hispanic & $59(97)$ \\
\hline Hispanic & $2(3)$ \\
\hline \multicolumn{2}{|l|}{ Socioeconomic status based on census tract } \\
\hline High socioeconomic status (<15\% below poverty level) & $27(44)$ \\
\hline Low socioeconomic status ( $\geq 15 \%$ below poverty level) & $34(56)$ \\
\hline \multicolumn{2}{|l|}{ Highest level of education completed } \\
\hline Less than high school & $4(6.5)$ \\
\hline High school/GED & $31(51)$ \\
\hline 2- or 4-year college & $18(29.5)$ \\
\hline Graduate education & $8(13)$ \\
\hline Currently enrolled in school & $12(20)$ \\
\hline Yes & $49(80)$ \\
\hline \multicolumn{2}{|l|}{ No } \\
\hline \multicolumn{2}{|l|}{ Currently employed ${ }^{a}$} \\
\hline No & $28(46)$ \\
\hline Full-time & $22(36)$ \\
\hline Part-time & $9(15)$ \\
\hline
\end{tabular}

aData missing from 2 participants.

pital medicine, neurology, or neurosurgery), and could attend a focus group within 30 days of the child's discharge. The majority of participants had a child admitted to hospital medicine; however, caregivers with a generally healthy child admitted to either neurology or neurosurgery were eligible to participate in the study.

\section{Study Design}

As presented elsewhere, ${ }^{17,20}$ we used focus groups and individual in-depth interviews to generate consensus themes about patient and caregiver experiences during the transition from hospital to home. Because there is evidence suggesting that focus group participants are more willing to talk openly when among others of similar backgrounds, we stratified the sample 


\section{TABLE 2. Major Theme 1 and Associated Subthemes}

Major Theme 1: Experiences that Affect Caregiver Perceptions of Communication between the Inpatient Medical Team and Families

\section{Positive Experiences}

Feeling like part of the team
"I thought it was above and beyond family-centric care, like I Feeling left out of felt like they really took me as the expert on my child and they the loop were like, 'What do you think?'...You know, I really felt like they actually waited for me to say 'Yeah, he is back to normal and I don't have, you know, a lot of concerns.'"

"They ask you if you think they're ready to be discharged. So, you don't get sent home in a situation that you're not really ready for."

\section{Negative Experiences}

eft out of "But when they shut it [the door], it's like you're in there and they're out there. And in order for me to get information you have to cross that threshold."

"I told them...I need to know what you're talking about. Some things I understand, so I won't ask about it, but some things that I don't understand, I would like you to, you know, to also include me...I'm the parent... it's important for me to know where you are getting all this information and how can it help me."

Insufficient face time "...I was more frustrated. So because they [physicians] will say they'll with physicians come back, but then they don't come back for 24 hours and stuff like that."

"There was one doctor, he was really nice, but he came in [and] I was sleeping. And I actually woke up to him standing in front of me... So you're asleep, you're exhausted, and he's like, 'Hi,' and like started talking. As soon as I opened my eyes, I'm like 'I need more time,' but he told me so much. And like two hours later, I could not remember anything we talked about."

Use of medical jargon "I think they shouldn't assume that everybody has a strong understanding of medical terms. I think they should just forget all their training and explain it..."

"If you're not familiar with the medical field, you don't know the terms."

\section{TABLE 3. Major Theme 2 and Associated Subthemes}

Major Theme 2: Communication Challenges for Caregivers Related to a Teaching Hospital Environment

Confusing messages with a large multidisciplinary team

"Well, on one hand like, you know the guy who did the surgery said to do this, and on the other hand they're [the medical team] saying not to, back and forth."

"I mean I understand it's a teaching hospital, they [residents] have to learn, but that kind of can get frustrating as a parent. We were getting told so many different things by different people."

"And [the primary medical team] seemed to think, 'Oh well, you know, I think it's this'--- and that specialist is like 'No, we don't think it's that... well there's nothing else we can really do, stop treating the symptoms, you can go and then [the primary medical team] didn't even call the medicines [into the pharmacy] to treat the symptoms."

Perceptions of family-centered rounds

"... They're talking amongst themselves with you in the room. You're trying to pick out what they're talking about...They did ask me if I want to join a round in the room, but now I think I would round outside the room because they are confusing...that's what happens with all the talking. Everybody talking at one time."

"And that [FCR] we found frustrating as well because he had headaches and the light and sound bother him and all of a sudden he would have 15 doctors that were standing in your room asking questions...I mean the lights are off for a reason...he's asleep."

"I got ambushed most of the time I was sleeping because [my daughter] would be up all night and I will get ambushed at 6 in the morning. There would be like 10 to 15 doctors... And they're like, 'Oh we're just here hun, is this a good time?' And like, I guess, let's just get this, but it could be a better time if they see me sleeping."

Role confusion: who's in charge of the team? "That was my confusion is there were so many different people. Like always so many people, who is the doctor, like I don't know."

"I basically figured out who was the chief of the whole group and I just pulled him to the side and ask him the questions to see what was going on."

"Because there's nobody really in charge. It's like one big team and so like one person is not responsible. So no one takes ownership."

NOTE: Abbreviation: FCR, family-centered rounds.

by the family's estimated socioeconomic status. ${ }^{21,22}$ Socioeconomic status was estimated by identifying the poverty rate in the census tract in which each participant lived. Census tracts, relatively homogeneous areas of $\sim 4000$ individuals, have been previously shown to effectively detect socioeconomic gradients. ${ }^{23-26}$ Here, we separated participants into 2 socioeconomically distinct groupings (those in census tracts where $<15 \%$ or $\geq 15 \%$ of the population lived below the federal poverty level). ${ }^{26}$ This cut point ensured an equivalent number of eligible participants within each stratum and diversity within our sample.

\section{Data Collection}

Caregivers were recruited on the inpatient unit during their child's hospitalization. Participants then returned to CCHMC fa- 
TABLE 4. Major Theme 3 and Associated Subthemes

Major Theme 3: Caregiver Perceptions of Communication Between Medical Providers

Communication between inpatient medical providers
"Finally, one doctor came in and said that the test results that they were waiting for would be around four o'clock, we could probably go home around that time ...but I have another doctor come in and say that there was a miscommunication. The results of her blood test couldn't come back until 10 o'clock that night...So that was kind of....kind of weird for me... Because I'm thinking, three different times, like three different messages about her test results being back in..."

"I guess my nurse switched in between the time at 11 or something... so the next nurse thought I was still waiting on the medicine and [child] already had the medicine and like an hour goes by and I'm like standing at the window like waiting for anyone to walk by. And somebody was like, 'do you need help?' And I'm like, 'can you send my nurse in? I think the first lady left."'

Communication between inpatient and outpatient providers

"I wasn't really clear on was did my primary already know what was happening, do you know what I mean?...[child] comes in, he gets even worse he's on a drip, he's on all the stuff... and I'm thinking like, does he know everything that happened? Or am I going to call and be like, 'Well he was in the hospital for five days and on the first day... and then he had six other medicines and then now what do I do' and you know or does he already have it? That's what I was unclear on. It's like, am I just calling any random person and say, hey, let me get some medical advice or does he have the charts, does he have the stuff?"

"And because she was so little, we took her to our primary care, our normal doctor... and she read over [the discharge paperwork] so they sent over the right paperwork and the dismissals to her, so it was necessary that she was informed and it helped out a lot..." cilities for the focus group within 30 days of discharge. Though efforts were made to enhance participation by scheduling sessions at multiple sites and during various days and times of the week, 4 sessions yielded just 1 participant; thus, the format for those became an individual interview. Childcare was provided, and participants received a gift card for their participation.

An open-ended, semistructured question guide, ${ }^{17}$ developed de novo by the research team, directed the discussion for focus groups and interviews. As data collection progressed, the question guide was adapted to incorporate new issues raised by participants. Questions broadly focused on aspects of the inpatient experience, discharge processes, and healthcare system and family factors thought to be most relevant to patient- and family-centered outcomes. Communication-related questions addressed information shared with families from the medical team about discharge, diagnoses, instructions, and care plans. An experienced moderator and qualitative research methodologist (SNS) used probes to further elucidate responses and expand discussion by participants. Sessions were held in private conference rooms, lasted $~ 90$ minutes, were audiotaped, and were transcribed verbatim. Identifiers were stripped and transcripts were reviewed for accuracy. After conducting 11 focus groups (generally composed of 5-10 participants) and 4 individual interviews, the research team determined that theoretical saturation ${ }^{27}$ was achieved, and recruitment was suspended.

\section{Data Analysis}

An inductive, thematic approach was used for analysis. ${ }^{27}$ Transcripts were independently reviewed by a multidisciplinary team of 4 researchers, including 2 pediatricians (LGS and AFB), a clinical research coordinator (SAS), and a qualitative research methodologist (SNS). The study team identified emerging concepts and themes related to the transition from hospital to home; themes related to communication during hospitalization are presented here.

During the first phase of analysis, investigators independently read transcripts and later convened to identify and define initial concepts and themes. A preliminary codebook was then designed. Investigators continued to review and code tran- scripts independently, meeting regularly to discuss coding decisions collaboratively, resolving differences through consensus. ${ }^{28}$ As patterns in the data became apparent, the codebook was modified iteratively, adding, subtracting, and refining codes as needed and grouping related codes. Results were reviewed with key stakeholders, including parents, inpatient and outpatient pediatricians, and home health nurses, throughout the analytic process. ${ }^{27,28}$ Coded data were maintained in an electronic database accessible only to study personnel.

\section{RESULTS}

\section{Participants}

Sixty-one caregivers of children discharged from CCHMC participated. Participants were $87 \%$ female and $46 \%$ nonwhite; $42.5 \%$ had a 2 -year college level of education or greater, and $56 \%$ resided in census tracts with $\geq 15 \%$ of residents living in poverty (Table 1). Participant characteristics aligned closely with the demographics of families of children hospitalized at CCHMC.

\section{Resulting Themes}

Analyses revealed the following 3 major communication-related themes with associated subthemes: (1) experiences that affect caregiver perceptions of communication between the inpatient medical team and families, (2) communication challenges for caregivers related to a teaching hospital environment, and (3) caregiver perceptions of communication between medical providers. Each theme (and subtheme) is explored below with accompanying verbatim quotes in the narrative and the tables.

\section{Major Theme 1: Experiences that Affect Caregiver Perceptions of Communication Between the Inpatient Medical Team and Families}

Experiences during the hospitalization contributed to caregivers' perceptions of their communication with their child's inpatient medical team. There were 5 related subthemes identified. The following 2 subthemes were characterized as positive experiences: (1) feeling like part of the team and (2) nurses as 
interpreters and navigators. The following 3 subthemes were characterized as negative: (1) feeling left out of the loop, (2) insufficient face time with physicians, and (3) the use of medical jargon (Table 2). More specifically, participants described feeling more satisfied with their care and the inpatient experience when they felt included and when their input and expertise as a caregiver was valued. They also appreciated how nurses often took the time after FCR or interactions with the medical team to explain and clarify information that was discussed with the patient and their caregiver. For example, 1 participant stated, "Whenever I ask about anything, I just ask the nurse. And if she didn't know, she would find out for me..."

In contrast, some of the negative experiences shared by participants related to feeling excluded from discussions about their child's care. One participant said, "They tell you... as much as they want to tell you. They don't fully inform you on things." Additionally, concerns were voiced about insufficient time for face-to-face discussions with physicians: "I forget what I have to say and it's something really, really important... But now, my doctor is going, you can't get the doctor back." Finally, participants discussed how the use of medical jargon often made it more difficult to understand things, especially for those not in the medical field.

\section{Major Theme 2: Communication Challenges for Caregiv- ers Related to a Teaching Hospital Environment}

At a large teaching institution with various trainees and multiple subspecialties, communication challenges were particularly prominent. Three subthemes were related to this theme: (1) confusing messages with a large multidisciplinary team, (2) perceptions of FCR, and (3) role confusion, or who's in charge of the team? (Table 3). Participants described confusing and inconsistent messages arising from the involvement of many medical providers. One stated, "When [the providers] all talk it seems like it don't make sense because [what] one [is] saying is slightly different [from] the other one... and then you'd be like, 'Wait, what?' So it kind of confuses you..." Similarly, the use of FCR was overwhelming for the majority of participants who cited difficulty tracking conversations, feeling "lost" in the crowd of team members, or feeling excluded from the conversation about their child. One participant stated, "But because so many people came in, it can get overwhelming. They come in big groups, like 10 at once." In contrast, some participants had a more favorable view of FCR: "What really blew me away was I came out of the restroom and there is 10 doctors standing around and they very well observed my child. And not only one doctor, but every one of them knew was going on with my kid. It kind of blew me away." Participants felt it was not always clear who was in charge of the medical team. Trying to remember the various roles of all of the team members contributed to this confusion and made asking questions difficult. One participant shared, "I just want the main people...the boss to come in, check the baby out. I don't need all the extra people running around me, keep asking me the same thing on that topic. Send in the main group, the bosses, they know what the problem is and how to fix it."
Major Theme 3: Caregiver Perceptions of Communication Between Medical Providers

Caregivers have a unique vantage point as they witness many interactions between medical providers during their child's hospitalization. Still, they do not generally witness all the interactions between inpatient providers or between inpatient and outpatient providers. This led to variable perceptions of this communication. Specifically, the 2 subthemes described here were (1) communication between inpatient medical providers and (2) communication between inpatient and outpatient providers (Table 4). Caregivers assessed how well (or how poorly) medical providers communicated with each other based upon the consistency of messages they received or interactions they personally experienced or observed. One participant described how the medical team did not appear to be in consensus about when to discharge her child, highlighting the perception that team members did not have a shared understanding of the child's needs: "One of the doctors was...nervous about sending him home. It was just one doctor...the other doctors on her team and everything and the nurses, they were like 'He's fine.'" Others shared concerns related to inadequate handoff and messages not getting passed along shift-to-shift.

Perceptions were not isolated to the inpatient setting. Based on their experiences, caregivers similarly described their sense of how inpatient and outpatient providers were communicating with each other. In some cases, it was clear that good communication, as perceived by the participant, had occurred in situations in which the primary care physician knew "everything" about the hospitalization when they saw the patient in follow-up. One participant described, "We didn't even realize at the time, [the medical team] had actually called our doctor and filled them in on our situation, and we got [to the follow up visit]...He already knew the entire situation." There were others, however, who shared their uncertainty about whether the information exchange about their child's hospitalization had actually occurred. They, therefore, voiced apprehension around who to call for advice after discharge; would their outpatient provider have their child's hospitalization history and be able to properly advise them?

\section{DISCUSSION}

Communication during a hospitalization and at transition from hospital to home happens in both formal and informal ways; it is a vital component of appropriate, effective patient care. When done poorly, it has the potential to negatively affect a patient's safety, care, and key outcomes. ${ }^{2}$ During a hospitalization, the multifaceted nature of communication and multidisciplinary approach to care provision can create communication challenges and make fixing challenges difficult. In order to more comprehensively move toward mitigation, it is important to gather perspectives of key stakeholders, such as caregivers. Caregivers are an integral part of their child's care during the hospitalization and particularly at home during their child's recovery. They are also a valued member of the team, particularly in this era of family-centered care. ${ }^{19,29}$ The perspectives of the caregivers presented here identified both successes and chal- 
lenges of their communication experiences with the medical team during their child's hospitalization. These perspectives included experiences affecting perceptions of communication between the inpatient medical team and families; communication related to the teaching hospital environment, including confusing messages associated with large multidisciplinary teams, aspects of FCR, and confusion about medical team member roles; and caregivers' perceptions of communication between providers in and out of the hospital, including types of communication caregivers observed or believed occurred between medical providers. We believe that these qualitative results are crucial to developing better, more targeted interventions to improve communication.

Maintaining a healthy and productive relationship with patients and their caregivers is critical to providing comprehensive and safe patient care. As supported in the literature, we found that when caregivers were included in conversations, they felt appreciated and valued; in addition, when answers were not directly shared by providers or there were lingering questions, nurses often served as "interpreters." 29,30 Indeed, nurses were seen as a critical touchpoint for many participants, individuals that could not only answer questions but also be a trusted source of information. Supporting such a relationship, and helping enhance the relationship between the family and other team members, may be particularly important considering the degree to which a hospitalization can stress a patient, caregiver, and family. ${ }^{31-34}$ Developing rapport with families and facilitating relationships with the inclusion of nursing during FCR can be particularly helpful. Though this can be challenging with the many competing priorities of medical providers and the fast-paced, acute nature of inpatient care, making an effort to include nursing staff on rounds can cut down on confusion and assist the family in understanding care plans. This, in turn, can minimize the stress associated with hospitalization and improve the patient and family experience.

While academic institutions' resources and access to subspecialties are often thought to be advantageous, there are other challenges inherent to providing care in such complex environments. Some caregivers cited confusion related to large teams of providers with, to them, indistinguishable roles asking redundant questions. These experiences affected their perceptions of FCR, generally leading to a fixation on its overwhelming aspects. Certain caregivers highlighted that FCR caused them, and their child, to feel overwhelmed and more confused about the plan for the day. It is important to find ways to mitigate these feelings while simultaneously continuing to support the inclusion of caregivers during their child's hospitalization and understanding of care plans. Some initiatives (in addition to including nursing on FCR as discussed above) focus on improving the ways in which providers communicate with families during rounds and throughout the day, seeking to decrease miscommunications and medical errors while also striving for better quality of care and patient/family satisfaction. ${ }^{35}$ Other initiatives seek to clarify identities and roles of the often large and confusing medical team. One such example of this is the development of a face sheet tool, which provides families with medical team members' photos and role descriptions. Unaka et al. ${ }^{36}$ found that the use of the face sheet tool improved the ability of caregivers to correctly identify providers and their roles. Thinking beyond interventions at the bedside, it is also important to include caregivers on higher level committees within the institution, such as on family advisory boards and/or peer support groups, to inform systems-wide interventions that support the tenants of family-centered care. ${ }^{29}$ Efforts such as these are worth trialing in order to improve the patient and family experience and quality of communication.

Multiple studies have evaluated the challenges with ensuring consistent and useful handoffs across the inpatient-to-outpatient transition, ${ }^{8-10,12}$ but few have looked at it from the perspective of the caregiver. ${ }^{13}$ After leaving the hospital to care for their recovering child, caregivers often feel overwhelmed; they may want, or need, to rely on the support of others in the outpatient environment. This support can be enhanced when outpatient providers are intimately aware of what occurred during the hospitalization; trust erodes if this is not the case. Given the value caregivers place on this communication occurring and occurring well, interventions supporting this communication are critical. Furthermore, as providers, we should also inform families that communication with outpatient providers is happening. Examples of efforts that have worked to improve the quality and consistency of communication with outpatient providers include improving discharge summary documentation, ensuring timely faxing of documentation to outpatient providers, and reliably making phone calls to outpatient providers. ${ }^{37-39}$ These types of interventions seek to bridge the gap between inpatient and outpatient care and facilitate a smooth transfer of information in order to provide optimal quality of care and avoid undesired outcomes (eg, emergency department revisits, readmissions, medication errors, etc) and can be adopted by institutions to address the issue of communication between inpatient and outpatient providers.

We acknowledge limitations to our study. This was done at a single academic institution with only English-speaking participants. Thus, our results may not be reflective of caregivers of children cared for in different, more ethnically or linguistically diverse settings. The patient population at CCHMC, however, is diverse both demographically and clinically, which was reflected in the composition of our focus groups and interviews. Additionally, the inclusion of participants who received a nurse home visit after discharge may limit generalizability. However, only 4 participants had a nurse home visit; thus, the overwhelming majority of participants did not receive such an intervention. We also acknowledge that those willing to participate may have differed from nonparticipants, specifically sharing more positive experiences. We believe that our sampling strategy and use of an unbiased, nonhospital affiliated moderator minimized this possibility. Recall bias is possible, as participants were asked to reflect back on a discharge experience occurring in their past. We attempted to minimize this by holding sessions no more than 30 days from the day of discharge. Finally, we present data on caregivers' perception of communication and not directly observed communication 
occurrences. Still, we expect that perception is powerful in and of itself, relevant to both outcomes and to interventions.

\section{CONCLUSION}

Communication during hospitalization influences how caregivers understand diagnoses and care plans. Communication perceived as effective fosters mutual understandings and positive relationships with the potential to result in better care and improved outcomes. Communication perceived as ineffective negatively affects experiences of patients and their caregivers and can adversely affect patient outcomes. Learning from caregivers' experiences with communication during their child's hospitalization can help identify modifiable factors and inform strategies to improve communication, support families through hospitalization, and facilitate a smooth reentry home.

\section{Acknowledgments}

This manuscript is submitted on behalf of the $\mathrm{H} 2 \mathrm{O}$ study group: Katherine $\mathrm{A}$. Auger, MD, MSc, JoAnne Bachus, BSN, Monica L. Borell, BSN, Lenisa V. Chang, MA, PhD, Jennifer M. Gold, BSN, Judy A. Heilman, RN, Joseph A. Jabour, BS, Jane C. Khoury, PhD, Margo J. Moore, BSN, CCRP, Rita H. Pickler, PNP, PhD, Anita N. Shah, DO, Angela M. Statile, MD, MEd, Heidi J. Sucharew, PhD, Karen P. Sullivan, BSN, Heather L. Tubbs-Cooley, RN, PhD, Susan Wade-Murphy, MSN, and Christine M. White, MD, MAT.

Disclaimer: All statements in this report, including its findings and conclusions, are solely those of the authors and do not necessarily represent the views of the Patient-Centered Outcomes Research Institute (PCORI), its Board of Governors, or Methodology Committee.

Disclosures: This work was (partially) supported through a Patient-Centered Outcomes Research Institute (PCORI) Award (HIS-1306-0081). The authors have no financial relationships relevant to this article to disclose. The authors have no conflicts of interest to disclose.

\section{References}

1. Riesenberg LA, Leitzsch J, Massucci JL, et al. Residents' and Attending Physicians' Handoffs: A Systematic Review of the Literature. Acad Med. 2009;84(12):1775-1787

2. The Joint Commission releases improving America's hospitals: a report on quality and safety. JT Comm Perspect. 2007;27(5):1, 3 .

3. Nobile C, Drotar D. Research on the quality of parent-provider communication in pediatric care: Implications and recommendations. J Dev Behav Pediatr. 2003;24(4):279-290.

4. Shoeb M, Merel SE, Jackson MB, Anawalt BD. "Can we just stop and talk?" patients value verbal communication about discharge care plans. J Hosp Med. 2012;7(6):504-507.

5. Giambra BK, Stiffler D, Broome ME. An integrative review of communication between parents and nurses of hospitalized technology-dependent children. Worldviews Evid Based Nurs. 2014;11(6):369-375.

6. Comp D. Improving parent satisfaction by sharing the inpatient daily plan of care: an evidence review with implications for practice and research. Pediat Nurs. 2011;37(5):237-242.

7. Khan A, Rogers JE, Melvin P, et al. Physician and Nurse Nighttime Communication and Parents' Hospital Experience. Pediatrics. 2015;136(5):e1249-e1258.

8. Coghlin DT, Leyenaar JK, Shen M, et al. Pediatric discharge content: a multisite assessment of physician preferences and experiences. Hosp Pediatr. 2014:4(1):9-15.

9. Harlan G, Srivastava R, Harrison L, McBride G, Maloney C. Pediatric hospitalists and primary care providers: A communication needs assessment. J Hosp Med. 2009;4(3):187-193.

10. Leyenaar JK, Bergert L, Mallory LA, et al. Pediatric primary care providers' perspectives regarding hospital discharge communication: a mixed methods analysis. Acad Pediatr. 2015;15(1):61-68

11. Ruth JL, Geskey JM, Shaffer ML, Bramley HP, Paul IM. Evaluating communication between pediatric primary care physicians and hospitalists. Clin Pediatr. 2011;50(10):923-928.

12. Solan LG, Sherman SN, DeBlasio D, Simmons JM. Communication Challeng- es: A Qualitative Look at the Relationship Between Pediatric Hospitalists and Primary Care Providers. Acad Pediatr. 2016;16(5):453-459.

13. Adams DR, Flores A, Coltri A, Meltzer DO, Arora VM. A Missed Opportunity to Improve Patient Satisfaction? Patient Perceptions of Inpatient Communication With Their Primary Care Physician. Am J Med Qual. 2016;31(6)568-576.

14. Hruby M, Pantilat SZ, Lo B. How do patients view the role of the primary care physician in inpatient care? Dis Mon. 2002;48(4):230-238.

15. Rao JK, Anderson LA, Inui TS, Frankel RM. Communication interventions make a difference in conversations between physicians and patients - A systematic review of the evidence. Med Care. 2007;45(4):340-349.

16. Banka G, Edgington $\mathrm{S}$, Kyulo N, et al. Improving patient satisfaction through physician education, feedback, and incentives. J Hosp Med. 2015;10(8):497-502.

17. Solan LG, Beck AF, Brunswick SA, et al. The Family Perspective on Hospital to Home Transitions: A Qualitative Study. Pediatrics. 2015;136(6):e1539-e1549.

18. Tubbs-Cooley HL, Pickler RH, Simmons JM, et al. Testing a post-discharge nurse-led transitional home visit in acute care pediatrics: the Hospital-To-Home Outcomes (H2O) study protocol. J Adv Nurs. 2016;72(4)915-925

19. Muething SE, Kotagal UR, Schoettker PJ, Gonzalez del Rey J, DeWitt TG. Family-centered bedside rounds: a new approach to patient care and teaching. Pediatrics. 2007;119(4):829-832.

20. Beck AF, Solan LG, Brunswick SA, et al. Socioeconomic status influences the toll paediatric hospitalisations take on families: a qualitative study. BMJ Qual Saf. 2017:26(4)304-311.

21. Crabtree BF, Miller WL. Doing Qualitative Research. 2nd ed. Thousand Oaks: Sage Publications; 1999.

22. Stewart D, Shamdasani P, Rook D. Focus Groups: Theory and Practice. 2nd ed. Thousand Oaks: Sage Publications; 2007.

23. Krieger N, Chen JT, Waterman PD, Rehkopf DH, Subramanian SV. Painting a truer picture of US socioeconomic and racial/ethnic health inequalities: the Public Health Disparities Geocoding Project. Am J Public Health. 2005;95(2):312-323.

24. Krieger N, Chen JT, Waterman PD, Soobader MJ, Subramanian SV, Carson $\mathrm{R}$. Geocoding and monitoring of US socioeconomic inequalities in mortality and cancer incidence: does the choice of area-based measure and geographic level matter?: the Public Health Disparities Geocoding Project. American J Epidemiol. 2002;156(5):471-482.

25. Krieger N, Waterman P, Chen JT, Soobader MJ, Subramanian SV, Carson R. Zip code caveat: bias due to spatiotemporal mismatches between zip codes and US census-defined geographic areas--the Public Health Disparities Geocoding Project. Am J Public Health. 2002;92(7):1100-1102.

26. Shonkoff JP, Garner AS; Committee on Psychosocial Aspects of Child and Family Health; Committee on Early Childhood, Adoption, and Dependent Care; Section on Developmental and Behavioral Pediatrics. The lifelong effects of early childhood adversity and toxic stress. Pediatrics. 2012;129(1):e232-e246

27. Patton MQ. Qualitative Research and Evaluation Methods. 3rd ed. Thousand Oaks: Sage Publications; 2002

28. Miles MB, Huberman AM, Saldaña J. Qualitative Data Analysis: A Methods Sourcebook. 3rd ed. Thousand Oaks: Sage Publications; 2014.

29. Kuo DZ, Houtrow AJ, Arango P, Kuhlthau KA, Simmons JM, Neff JM. Family-centered care: current applications and future directions in pediatric health care. Matern Child Health J. 2012;16(2):297-305.

30. Latta LC, Dick R, Parry C, Tamura GS. Parental responses to involvement in rounds on a pediatric inpatient unit at a teaching hospital: a qualitative study. Acad Med. 2008;83(3):292-297.

31. Bent KN, Keeling A, Routson J. Home from the PICU: are parents ready? MCN Am J Matern Child Nurs. 1996;21(2):80-84.

32. Heuer L. Parental stressors in a pediatric intensive care unit. Pediatr Nurs. 1993:19(2):128-131.

33. Lapillonne A, Regnault A, Gournay V, et al. Impact on parents of bronchiolitis hospitalization of full-term, preterm and congenital heart disease infants. BMC Pediatr. 2012:12:171-181.

34. Leidy NK, Margolis MK, Marcin JP, et al. The impact of severe respiratory syncytial virus on the child, caregiver, and family during hospitalization and recovery. Pediatrics. 2005:115(6):1536-1546.

35. Bringing I-PASS to the Bedside: A Communication Bundle to Improve Patient Safety and Experience. http://www.pcori.org/research-results/2013/ bringing-i-pass-bedside-communication-bundle-improve-patient-safety-and. Accessed on December 1, 2016.

36. Unaka NI, White CM, Sucharew HJ, Yau C, Clark SL, Brady PW. Effect of a face sheet tool on medical team provider identification and family satisfaction. J Hosp Med. 2014;9(3):186-188

37. Mussman GM, Vossmeyer MT, Brady PW, Warrick DM, Simmons JM, White $\mathrm{CM}$. Improving the reliability of verbal communication between primary care physicians and pediatric hospitalists at hospital discharge. J Hosp Med. 2015;10(9):574-580.

38. Key-Solle M, Paulk E, Bradford K, Skinner AC, Lewis MC, Shomaker K. Improving the quality of discharge communication with an educational intervention. Pediatrics. 2010;126(4):734-739.

39. Harlan GA, Nkoy FL, Srivastava R, et al. Improving transitions of care at hospital discharge--implications for pediatric hospitalists and primary care providers. J Healthc Qual. 2010;32(5):51-60. 